\title{
MERCANTILIZAÇÃO DO ESPAÇO URBANO E SUAS IMPLICAÇÕES NA CONCEPÇÃO DE CIDADES JUSTAS, DEMOCRÁTICAS, INCLUSIVAS E HUMANAS
}

\section{MERCANTILIZATION OF URBAN SPACE AND ITS IMPLICATIONS IN THE CONCEPT OF FAIR, DEMOCRATIC, INCLUSIVE AND HUMAN CITIES}

\section{Daniel Rubens Cenci ${ }^{1}$ Geciana Seffrin ${ }^{2}$}

\section{Resumo}

O direito à cidade, sob a perspectiva dos direitos humanos é permeado por um conjunto de temas bastante amplo e complexo. Com esta temática o presente artigo analisa o direito à cidade, os principais fatores que impedem, dificultam ou simplesmente influenciam de alguma maneira, a materialização de cidades sustentáveis num sentido mais abrangente. Realiza-se uma breve explicação acerca dos principais efeitos e influências da mercantilização do espaço urbano no processo de materialização de cidade mais justas, democráticas, humanas e inclusivas. Para alcançar os resultados da proposta, o trabalho é elaborado mediante pesquisa bibliográfica e documental, orientada no método de abordagem hipotético-dedutivo, adotando como método de procedimento o método histórico e comparativo sendo, por fim, adotado o método sociológico de análise e interpretação. A superação das contradições do contexto que mercantiliza o espaço urbano, apresenta-se como passo fundamental para solucionar a crise urbana que se mostra insustentável, na qual o aumento da riqueza de alguns exacerba a miséria de outros, refletindo-se na necessidade de combinar a adoção de estratégias de inclusão social que fortaleçam a democracia, a equidade, a descentralização da riqueza e do poder, valorizando os processos de desenvolvimento local, em vista de cidades mais justas e inclusivas.

Palavras-chave: Direito à moradia; Direitos humanos; Inclusão social; Políticas habitacionais;

\footnotetext{
${ }^{1}$ Pós-Doutor em Geopolítica Ambiental Latinoamericana (USACH - Universidade de Santiago do Chile); Doutor em Meio Ambiente e Desenvolvimento pela Universidade Federal do Paraná (UFPR); Professor do Programa de Pós-Graduação em Direito - Mestrado em Direitos Humanos - e do Curso de Graduação em Direito (UNIJUI); Coordenador do Grupo de Pesquisa (CNPq): Cidade, Saúde e Sustentabilidade. Email: danielr@unijui.edu.br

${ }^{2}$ Mestre em Direito em Direitos Humanos pela UNIJUI/RS Especialista em Direito Público com Ênfase em Gestão Pública para o Ensino no Magistério Superior pela Faculdade Damásio; Advogada; Procuradora Geral do Município de Três Passos/RS. E-mail: gecianas@gmail.com.br
} 
Mercantilização do espaço urbano.

\begin{abstract}
The right to the city, from the human rights perspective, is permeated by a very broad and complex set of themes. With this subject, the present article analyzes the right to the city as well as the main factors that block, hamper or simply influence in any way, the materialization of sustainable cities in a more comprehensive sense. A brief exploration has been done over the main effects and influences of the commercialization of urban space in the process of materialization of cities that are more fair, democratic, human and inclusive. In order to reach the results of the proposal, the study has been elaborated through bibliographical and documentary research, based through the hypothetical-deductive method of approach, adopting the historical and comparative method of procedure, being, finally, adopted the sociological method of analysis and interpretation. The overcoming of the contradictions from the context that commercializes the urban space, presents itself as a fundamental step to solve the urban crisis that is unsustainable, in which the increase of the wealth of some individuals exacerbates the misery of others, reflecting on the need to combine the adoption of social inclusion strategies that strengthen democracy, fairness, decentralization of wealth and power, valuing local development processes, through the scope of fairer and more inclusive cities.
\end{abstract}

Keywords: Right to housing; Human rights; Social inclusion; Housing policies; Mercantilization of urban space.

\title{
INTRODUÇÃO
}

A constituição da problemática que envolve o direito à cidade é bastante complexa e está intrinsecamente relacionada com o processo de urbanização, isto é, a transformação do território vazio em cidades ainda se revela um cenário bastante carregado pela luta por direitos. Nesta senda, o presente trabalho objetiva analisar o conjunto de situações que envolve a questão urbana no Brasil, retratada através das influências da mercantilização do espaço urbano na concepção de cidades justas, democráticas, inclusivas e humanas

Malgrado os inúmeros esforços legislativos e os avanços ocorridos nas formas de organização político-jurídica dos Estados, realizados também com o desígnio de efetivar o direito humano à cidade no Brasil, é possível perceber que o sistema capitalista reproduz 
irreparáveis distorções sociais até hoje. No cenário atual, importante referir, a moradia, o uso do solo e sua regulação experimentam direta e intensa interferência do mercado, que acaba definindo o valor da moradia e dos espaços urbanos de acordo com as especulações imobiliárias, tornando ainda mais acentuada a concentração fundiária e de renda de um lado e, de outro lado, a segregação e a exclusão socioespacial.

Essa realidade, reforçada pelo crescimento desordenado das cidades - decorrência da ausência de planejamento e da frágil gestão urbanística -, tem propiciado inúmeros transtornos sociais, econômicos e ambientais, reforçando a exclusão social e a marginalização dos grupos sociais com menor poder aquisitivo, conjuntura que os distancia cada vez mais de uma moradia adequada e do direito a uma cidade sustentável.

Neste contexto, ao longo deste trabalho será abordada a problemática que envolve a efetivação do direito à cidade sob a ótica dos direitos humanos, bem como os reflexos que a composição de espaços organizadas sob um sistema capitalista podem acarretar na efetivação deste direito fundamental, sobretudo no que diz respeito aos efeitos decorrentes da mercantilização do espaço urbano e seus nefastos efeitos incidentes na concretização dos direitos sociais.

A hipótese a ser trabalhada destina-se a abordar a questão da mercantilização do direito à moradia e do solo urbano no contexto de cidades capitalistas como o principal fator de influência no surgimento e reprodução de espaços cada vez mais marcados pela segregação socioespacial, e como a fragilidade da atuação estatal nas demandas afetas à política pública habitacional contribui para o crescimento das desigualdades sociais e o esvaziamento do discurso sobre os direitos humanos.

Diante dessa conjuntura se entende pertinente provocar algumas reflexões acerca desta necessária interligação do direito humano à cidade como elemento essencial da dignidade da pessoa humana, e a função do Estado Democrático de Direito para garantir a concretização de ambos, e, também, como forma de viabilizar a construção de uma sociedade mais livre, justa e solidária.

\section{INFLUÊNCIAS DA MERCANTILIZAÇÃO DO ESPAÇO URBANO NA CONCEPÇÃO DE CIDADES JUSTAS, DEMOCRÁTICAS, INCLUSIVAS E HUMANAS}

O núcleo de estudo relativo ao direito humano à cidade é objeto de análise em diversas ciências, não se detendo apenas às ciências jurídicas e sociais, principalmente pela sua 
pluralidade de aspectos essenciais à vida humana. Trata-se de incontestável direito humano, uma vez que não apenas figura como condição capital para a vida digna, mas, sobretudo, em função de sua conexão direta com outros tantos direitos também considerados essenciais para a dignidade da pessoa humana.

Partido desta premissa, a compreensão do direito a cidade sob a perspectiva dos direitos humanos, ou seja, a compreensão da cidade enquanto um espaço justo, democrático, inclusivo e humano se releva como um importante instrumento acadêmico, social e político para facilitar a compreensão da complexa teia de relações que envolve a vida na sociedade contemporânea global, e como o desenvolvimento desordenado dos espaços pode trazer severas consequências para o bem-estar e a qualidade de vida dos citadinos.

O padrão de crescimento urbano no Brasil é um reflexo, em grande medida, das formas de intervenção do Estado, por meio de suas políticas públicas, aliado a ausência ou precariedade de planejamento para as cidades, que, ao longo dos anos, têm refletido diretamente no agravamento da segregação e exclusão socioespacial, crescimento das periferias e consolidação de um mercado imobiliário cada vez mais restritivo e especulativo.

O conturbado percurso histórico de desenvolvimento urbanístico faz com que a maior parte dos brasileiros seja privado do convívio de cidades justas, democráticas, inclusivas e humanas, especialmente em face da valorização das ações de cunho capitalista em detrimento das ações de cunho social. O Brasil ainda está distante priorizar a dimensão social do desenvolvimento, de sorte que se mostra de bom alvitre analisar os fatores que impedem, dificultam ou simplesmente influenciam de alguma maneira a materialização de cidades sustentáveis (em sentido amplo) no cenário nacional.

Diante disso, se mostra bastante oportuno analisar, os principais elementos que compõem a financeirização do direito à moradia e seus reflexos na concepção das cidades modernas.

\section{Mercantilização do direito à moradia e seus reflexos na concepção das cidades modernas}

Seguindo uma tendência internacional, a partir do final do século XX e início do século XXI, tem se tornado cada vez mais evidente o surgimento de um novo perfil econômico, proporcionado, especialmente, pelas inovações do mercado financeiro (sobretudo com o surgimento do modelo de Estado Neoliberalista), que não se restringem mais às atividades 
clássicas de crédito.

Com efeito, no decorrer das últimas décadas as inovações verificadas no mercado financeiro têm apresentando, entre outros resultados e consequências, a transformação das propriedades urbanas em um dos ativos financeiros mais importantes, situação que impacta diretamente na dinâmica das cidades, principalmente nas cidades modernas.

Consoante ensina Milton Santos (2012, p. 30-32), o espaço, ao longo dos anos, foi se tornando "a mercadoria universal por excelência", ou seja, "um capital comum a toda humanidade. Entretanto, sua utilização efetiva é reservada àqueles que dispõem de um capital particular." Como consequência desta realidade, é reforçada a ideia trazida no item anterior acerca da centralidade da propriedade privada e suas implicações na era do capital, além de potencializar a segregação socioespacial.

Os efeitos desta nova lógica econômica e de organização do espaço urbano, assim como as consequências daí advindas, serão analisados com maior ênfase a partir de agora, especialmente pelas influências que exercem na construção de cidades mais justas, democráticas, inclusivas e humanas.

A organização das cidades e a atuação Estado como influências negativas no processo de mercantilização da moradia e da segregação socioespacial

Com o passar do tempo a história foi fazendo registro dos diferentes fenômenos que permearam, inicialmente, o surgimento do espaço urbano e, em sequência, as suas diferentes formas de organização. Assim, sem maiores dificuldades, é possível verificar, de forma rápida e direta, que o nascimento e desenvolvimento das cidades passa pelas antigas cidades muradas da era medieval até chegar nas gigantescas metrópoles contemporâneas.

Em face destes fenômenos tão distintos, há certa dificuldade em definir o conceito do elemento cidade. Filiando-se à poética concepção de Raquel Rolnik (1995, p. 13), a abordagem que se faz da cidade neste trabalho parte da concepção da cidade como imã, ou seja, "a cidade é antes de mais nada um imã, antes mesmo de se tomar local permanente de trabalho e moradia", é o local de atração das pessoas.

Sem embargo de outras definições, perceber a cidade como imã parece traduzir a verdadeira essência de sua gênese. Isso porque, de fato, a partir do momento em que a sociedade começou a transformar o seu modo de vida, plantando ao invés de apenas coletar ou caçar, igualmente passou a ter início uma transformação na forma de ocupação do espaço pelo 
homem, instituindo-se uma nova relação entre o homem e a natureza, mediada então pela cidade.

No entanto, mais do que simples local de produção, a cidade também passa a ser local de moradia e trabalho, surgindo, efetivamente, quando a produção ali realizada começa a gerar excedentes. Segundo Rolnik (1995, p. 16):

O excedente é, ao mesmo tempo, a possibilidade de existência da cidade - na medida em que seus moradores são consumidores e não produtores agrícolas - e seu resultado - na medida em que é a partir da cidade que a produção agrícola é impulsionada. Ali são concebidas e administradas as grandes obras de drenagem e irrigação que incrementam a produtividade da terra; ali se produzem as novas tecnologias do trabalho e da guerra. Enfim, é na cidade [...] que se registra a acumulação de riquezas, de conhecimentos.

No entanto, é preciso destacar que, para além de produzir, morar e trabalhar, viver em cidades implica, involuntariamente, na necessidade de se viver de forma coletiva. Justamente desta necessidade de se organizar a vida coletiva da cidade é que emerge a indispensabilidade de se constituir um poder urbano incumbido de sua gestão

Ao aglomerar pessoas em razão, principalmente, da possibilidade de moradia e trabalho, e organizá-las politicamente através da figura do Estado, as cidades tornam-se locais de troca dos excedentes e colaboração entre os indivíduos, o que acarreta na potencialização de sua capacidade produtiva e faz surgir a figura do mercado.

A partir desta nova configuração de cidade, qualificada pela expansão do seu caráter mercantil, é que têm origem as cidades capitalistas, que predominam atualmente, e atraem cada vez mais a população para o espaço urbano. Vale dizer, é essa transformação das cidades, que passam de singelas vilas de camponeses para cidades de capital, que materializam uma drástica reestruturação na sua forma de organização.

Conforme aponta Raquel Rolnik (1995, p. 43), o primeiro fator que influência diretamente na reestruturação da forma de organização das cidades é a questão da "mercantilização do espaço urbano, ou seja, a terra urbana, que era comunalmente ocupada, passa a ser uma mercadoria - que se compra e vende como um lote de bois, um sapato, uma carroça ou um punhado de ouro."

O segundo fator de influência, continua Rolnik (1995, p. 43), é a divisão da sociedade em classes: de um lado os "proprietários dos meios de produção, os ricos detentores do dinheiro e bens; de outro, os vendedores de sua força de trabalho, os livres e despossuídos."

Com efeito, torna-se perceptível que a redefinição do espaço urbano, ou seja, a redefinição do espaço das cidades, marcada pela divisão, pela mercantilização da terra e da 
moradia, traz consigo inúmeros reflexos que repercutem ainda hoje nas cidades contemporâneas, sobretudo porque a separação do espaço urbano tendo como base suas funções e suas classes sociais acarreta em um movimento cada vez mais rijo de segregação espacial, fenômeno que será analisado com maior relevo a seguir.

Segregação socioespacial: a face perversa da financeirização do direito à moradia e do solo urbano

Abordar a questão da segregação socioespacial é um exercício que remete, imediatamente, ao ideário de um espaço demarcado, um espaço separado por cercas (ainda que imaginárias) que estabelecem, em quase perfeita ordem, o exato lugar onde cada coisa e cada pessoa deve estar.

Raquel Rolnik faz um retrato exato desta realidade demonstrando como ela pode, muitas vezes, ser praticamente imperceptível e, em razão disso, tornar-se naturalizada (e ainda mais cruel). Para a autora (1995, p. 45-46):

Meninas pulando corda e jogando amarelinha, fechadas no pátio da escola, se separam da rua por uma muralha de verdade [...]; já a fronteira entre um bairro popular e um bairro chique pode ser uma rua, uma ponte, ou simplesmente nada muito aparente [...]

Mas não é apenas a separação de territórios e classes sociais que caracterizam a segregação. Ademais de representar um recorte de classe, faixa etária ou raça, outra face da segregação também é expressa pela separação havida entre os locais de trabalho e os locais de moradia, ou seja, há uma nítida separação das funções de trabalhar e morar no contexto das cidades.

Não é incomum, principalmente em cidades maiores, que se vislumbre a hecatombe diária vivida por expressiva massa de trabalhadores que se deslocam de seus locais de moradia para os locais de trabalho ou estudo utilizando-se de transporte coletivo lotados e precários ou enfrentando engarrafamentos, percorrendo enormes distâncias diariamente. Além de tempo, essa triste expressão da segregação custa muito dinheiro e, muitas vezes, compromete significativamente a qualidade de vida dessas pessoas.

Em decorrência desta separação das funções do local de moradia e do local de trabalho e/ou estudo, ocorre um fenômeno instigante: inúmeros bairros das cidades ficam completamente vazios durante o dia (tornam-se os chamados "bairros-dormitórios"), ao passo que, durante a noite, são centros comerciais que se tornam espaços com quase completa 
ausência de vida humana, evidenciando ainda mais os reflexos negativos da ausência de planejamento urbano.

Outra face mórbida da segregação socioespacial se reflete no tratamento diferenciado que é conferido pelo Governo local a estes lugares e populações ficticiamente separados. É comum, por exemplo, que locais centrais tenham coleta de lixo mais frequente em relação às periferias, assim como tenham melhor estrutura no que se refere aos serviços básicos de luz, água, esgoto e segurança por exemplo, que acaba por reproduzir ainda mais a segregação.

Fazendo uma análise histórica perfunctória acerca da segregação socioespacial, Rolnik (1995) salienta que ela apenas passa a se tornar mais notória à proporção que progride a mercantilização da sociedade e se organiza o Estado Moderno. Com efeito, é a partir do momento em que o Estado escolhe suas sedes e as constrói, que se demarca o coração das cidades.

Em decorrência deste fenômeno, os sujeitos que possuíam relação direta com o Estado (seus principais funcionários, banqueiros ou comerciantes do alto escalão), passaram a construir suas moradias em bairros distintos do local de trabalho (até em então, não havia importância essa separação), dando origem a bairros bastante homogêneos do ponto de vista social. Segundo o entendimento de Rolnik (1995, p. 52), "este é o primeiro movimento de segregação - com ele vem o bairro dos negócios e uma reconceituação da moradia, que em sua acepção burguesa vem sob o signo da privacidade e do isolamento."

Ainda, merece referência outro fator que ajudou sobremaneira a impulsionar o movimento de segregação que foi a difusão, em larga escala, do trabalho assalariado. Rompendo com o vínculo da escravidão, também se rompe a servidão havida até então entre empregado e empregador e, consequentemente, o trabalhador, através do seu salário, deve prover seu próprio sustento e de sua família, assim como adquirir sua própria moradia. Esta circunstância faz com que igualmente se separe fisicamente o território, na medida em que tanto o empregado quanto o empregador comprarão no mercado imobiliário a moradia na localização que sua condição financeira permitir.

Há que se destacar, também, que soma-se às características já expostas da segregação espacial a sua face de conteúdo político, isto é, a segregação enquanto conflito, enquanto luta por espaço. Esta luta por espaço pode ser traduzida na "ameaça" sentida pela classe dominante com a aproximação do território popular, que pode contaminar de desordem o seu lugar da vida. Em relação diametralmente oposta, é justamente esta luta por espaço que viabiliza o surgimento e organização de territórios populares, que constituem o alicerce de luta dos 
trabalhadores pela apropriação do espaço urbano.

A trajetória da segregação socioespacial é marcada, precipuamente, por bases de cunho econômico especulativo e de cunho político. Do ponto de vista econômico, ela se relaciona diretamente com a financeirização de bens essenciais para a vida cotidiana, em especial o solo urbano e a mordia. Do ponto de vista político, se traduz como produtora e produto do conflito social, ou seja, é necessário separar para evitar conflitos, e quanto mais se separa, mais visível se torna a diferença.

Feita esta breve explanação acerca da organização das cidades e de como a atuação do Estado pode facilitar a financeirização da moradia e da segregação socioespacial, bem como após analisar de forma breve, mas direta, de como a segregação socioespacial pode se tornar perversa para a sociedade, será feita investigação que tem como objetivo principal trazer à luz como ocorreu o processo de financeirização do solo urbano e da moradia no Brasil e quais os reflexos daí advindos.

O processo de financeirização do solo urbano e da moradia no cenário $\underline{\text { brasileiro }}$

A partir deste tópico, tendo como ponto de apoio as sustentações anteriores, a pretensão é situar o debate e a reflexão acerca do processo de financeirização da moradia e do solo urbano no enredo das transformações havidas no Brasil, especialmente a partir do final do século XX e nas primeiras décadas do século XXI.

Esse recorte histórico se justifica na medida em que é justamente durante este lapso temporal que um dos principais itens de discurso e luta na agenda política é a criação de um Estado de direito, onde o direito à moradia adequada e, igualmente, o direito à cidade, constituíssem elementos de extrema importância para sua concretização. Sob outra perspectiva, é também neste mesmo período que o país se vê atingido com maior força pelas ondas do capitalismo globalizado e pelas pautas neoliberais, caracterizando este momento com ambivalências e paradoxos.

O processo de financeirização como um dos reflexos da criação do Banco Nacional de Habitação (BNH) e da introdução do Plano Real

Há muitas décadas a política habitacional brasileira é marcada pela concepção do ideal 
da "casa própria". Foi no período imediato após o foi da Segunda Guerra Mundial, por exemplo, que um ramo especializado do setor imobiliário passou a operar como verdadeiro mercado de casas próprias, impulsionando o segmento naquele setor.

No entanto, foi somente após o Golpe Militar de 1964 que se instituiu, pelo Governo, um banco público voltado especialmente para o setor de financiamento habitacional, o chamado Banco Nacional de Habitação (BNH), além de outros instrumentos financeiros, como as letras imobiliárias, por exemplo, que passaram a compor o Sistema Financeiro de Habitação (SFH).

Em face do regime ditatorial instaurado naquele período, a principal finalidade nascida paralelamente com o BNH era a construção de milhões de casas para os brasileiros de classe média, como forma de transformar essa parcela da população em verdadeiros conservadores, além de defensores do direito de propriedade. Adotando essa política habitacional, que se baseava na construção da casa própria, o Governo acreditava que estaria criando mais um instrumento de confronto às ideologias comunistas e progressistas do país, tendo como aliados "os novos proprietários.".

Segundo ensina Bonduki (2008), no entanto, foi o papel econômico desta "política habitacional - que dinamizou a economia, através da geração de empregos e fortalecimento do setor da construção civil - que a transformou num dos elementos centrais da estratégia dos governos militares."

Desta maneira, é possível aduzir que desde a criação do BNH até os dias atuais, estabeleceu-se um terreno de conflito, mas, também, de confluência entre aquilo que Rolnik (2015, p. 282) chama de "três dimensões decorrentes da definição de um organismo financeiro com locus de formulação e implementação da política habitacional e da opção originárias de fazer cada brasileiro um proprietário."

Segundo a autora (2015), a primeira dimensão refere-se ao fato de a política depender e incidir diretamente sobre os procedimentos fiscais e monetários do país. A segunda dimensão, por outro lado, relaciona-se com a ideologia política fundamentada na necessidade de redução do déficit habitacional, ou seja, reside na ideia de que o problema habitacional resolve-se a partir da construção de mais casas próprias. Por fim, a terceira dimensão diz respeito a um mecanismo de estímulo ao setor da construção civil, além de, por óbvio, fomentar o próprio setor financeiro.

Com facilidade é possível constatar que estas três dimensões alternaram-se, ao longo dos anos da história do SFH, recebendo maior ou menor destaque do Governo, na medida em 
que derivam diretamente da influência política dos diversos interesses articulados em torno da questão da habitação nacional. Assim, conforme era o ideário e a influência dos interesses políticos, em determinado momento houve o protagonismo de incentivos à indústria de construção civil, em outros momentos, porém, o protagonismo ficou a cargo da produção em massa de novas unidades habitacionais, e assim sucessivamente. Essa alternância continuou existindo inclusive após a extinção do BNH, que ocorreu em 1986.

Foi também durante esse período pós Segunda Guerra Mundial e durante a ditadura militar que o Governo criou o Fundo de Garantia por Tempo de Serviço (FGTS), formado basicamente pela contribuição de empregados e empregadores, a fim de constituir uma "poupança compulsória" ao trabalhador.

Segundo Luciana de Oliveira Royer (2014), a grandiosidade dos recursos que passaram a se acumular em decorrência da criação do FGTS, elevaram o BNH à condição de segundo estabelecimento bancário de Brasil de maior relevância, transformando-o, igualmente, na principal fonte de recursos para a política habitacional e de saneamento.

A elevação do FGTS a este status traz como principal consequência o fortalecimento da dimensão financeira da política habitacional, sobretudo porque as decisões acerca de para quem, como e onde é mais adequado investir, por exemplo, passam a ficar sob o julgamento de um estabelecimento bancário que, diga-se, foi transformado em empresa pública ainda no ano de 1966. Em outras palavras, os rumos da política habitacional passam a ser conduzidos diretamente pelos interesses do mercado.

Para Royer (2014, p. 55)

Isso explica, em parte, porque apenas $30 \%$ do total de 4,5 milhões de financiamentos habitacionais concedidos através do BNH, entre 1970 e 1986, tenha se dirigido aos setores de menor renda. Explica, igualmente, a diversificação dos investimentos do banco, que na década de 1970 passa a financiar também grandes obras de infraestrutura [...]

Em que pese a grande influência experimentada pelo BNH desde a sua criação, a instituição não resistiu à crise de liquidez armada em decorrência do quadro inflacionário, tampouco resistiu ao aumento da recessão e da inadimplência, que tomaram por gerar um grande desfalque nas contas do banco, levando a sua extinção, em 1986.

Após a extinção do BNH, houve uma descontinuação na política habitacional como um todo e, em especial, de construção da casa própria. Além disso, o país experimentou, na década de 80 , um período de recessão econômica, que representou uma significativa "retração da atividade imobiliária e do financiamento habitacional" (ROLNIK, 2015, p. 286).

Ainda, segundo Rolnik (2015, p. 286), este cenário de retração da economia e 
estagnação do financiamento habitacional só começa a mudar a partir de meados "dos anos 1990, quando reformas tanto no modelo de regulação do crédito habitacional quanto na estrutura e composição do capital das empresas envolvidas no mercado imobiliário residencial passam a ser implementadas", o que será melhor analisado a partir deste momento.

A principal reforma experimentada na década de 90 consistiu na criação do Plano Real. O Plano Real foi instituído no Brasil em junho de 1994, e consistia em materializar um modelo econômico que tinha como principal objetivo reduzir e controlar a inflação que assolava o momento, estabilizando a economia. Como ponto de partida, o Plano Real inaugurou uma nova moeda, promovendo uma verdadeira reforma no sistema financeiro nacional, representada, sobretudo, pela abertura do mercado financeiro nacional aos bancos estrangeiros.

Consoante salienta Rolnik (2015, p. 286), "o setor imobiliário foi um alvo importante das reformas liberalizantes levadas a cabo no mesmo período". As novas propostas do ramo imobiliário introduzidas a partir dos anos 90 pretendiam ampliar a participação do capital financeiro neste setor e, para concretizar esta ideia, foram lançadas diversas novidades como a introdução de operações de companhias securitizadoras de créditos imobiliários, a criação de fundos de investimentos imobiliários, entre outros.

Entretanto, para que essas novidades tivessem êxito, mostrou-se imprescindível fortalecer as garantias para o retorno dos investimentos que seriam feitos. Para que isso se tornasse possível, no mesmo período foi constituída a possibilidade de alienação fiduciária, ou seja, tornou-se possível a realização de contratos imobiliários onde a propriedade jurídica do imóvel era mantida com o credor até o pagamento integral do débito, momento a partir do qual o tomador do financiamento conquista o título de proprietário.

Essa inovação trouxe consigo duas percepções distintas. Do ponto de vista dos investidores, mostrou-se uma conquista bastante positiva, pois inaugurava um marco regulatório imobiliário orientado para o mercado. Por outro lado, esta situação revelou-se muito prejudicial aos moradores, que poderiam perder suas casas caso não conseguissem garantir o pagamento das prestações do financiamento.

Com efeito, é possível estabelecer que a partir dessas inovações trazidas a partir da introdução do Plano Real que a política habitacional começou a tomar a forma que a modela atualmente, tendo sido aprimorada em vários aspectos, e inovada em muitos outros, conforme se ilustrará no tópico seguinte. 
O processo de financeirização após 1995 até a contemporaneidade

Durante o governo do Presidente Fernando Henrique Cardoso (1995 a 2002), a sociedade pôde presenciar um período de enraizamento da pauta neoliberal, onde a efetivação dos direitos sociais previstas na Constituição Federal recém promulgada tornou-se agenda secundária, dando espaço para o protagonismo de um modelo de administração que preocupou-se em retrair ao máximo a intervenção estatal, além de ajustar e consolidar as instituições de mercado, investindo em privatizações, principalmente nas áreas de comunicação e petróleo, bem como na eliminação de restrições ao capital estrangeiro.

O governo do Presidente Luiz Inácio da Silva (2003 a 2011), e depois, de sua sucessora Dilma Roussef (2012 a 2016), por seu turno, foi marcado pela não interrupção da estabilidade econômica proporcionada pelo Governo de FHC, além do combate à inflação, ampliação das exportações e formas de contenção de despesas. Essa postura política dos governantes petistas proporcionou a criação de frentes assistencialistas que desenvolveram programas sociais com vistas a enfrentar o grave problema da concentração de renda do país.

No campo dos direitos sociais, é preciso destacar que, especialmente nos anos de 1999 a 2009, a sociedade brasileira assistiu a implementação de diversas políticas públicas direcionadas à camada mais miserável da população, sobretudo através de programas de transferência de renda, como é o caso do Bolsa Família, por exemplo, que tinha como finalidade principal retirar essa camada da população do nível de miserabilidade em que se encontrava.

Para Maricato (2011), esta estratégia aparentemente obteve êxito, sobretudo porque com a ampliação dos rendimentos do trabalho e da expansão das ofertas de emprego, que repercutiram positivamente na previdência social, o número de pessoas consideradas pobres no Brasil caiu de 30\% para 15\% da população, no período compreendido entre 2001 e 2008, principalmente em decorrência do aumento do valor do salário mínimo e da política de transferência de renda direta aos setores vulneráveis da sociedade.

Nesta mesma temporada, houve a retomada dos bancos e fundos públicos no fornecimento de crédito e no impulsionamento dos investimentos tanto públicos quanto privados, proporcionados através da implementação de programas como o Programa de Aceleração do Crescimento (PAC) e do Programa Minha Cava Minha Vida (PMCMV), que não apenas incluíram grandes obras e investimentos em infraestrutura, saneamento e urbanização de favelas como, igualmente, ampliaram sobremaneira as formas de concessão de subsídios públicos para a construção de casas particulares. 
Precisamente no que toca à política urbana, Raquel Rolnik (2009) salienta que neste período houve o fortalecimento dos intensos avanços no campo do direito à moradia e do direito à cidade, objeto de luta nas décadas de 80 e 90, especialmente em face do acentuado debate havido entre a sociedade civil, partidos políticos e governos a respeito do papel das organizações sociais e dos cidadãos na formulação da política urbana e na gestão das cidades.

O resultado mais expressivo, talvez, destes avanços tenha sido a inclusão, na Constituição Federal de 1988, de um capítulo próprio para tratar da política urbana, baseado, precipuamente, no cumprimento da função social da propriedade e no reconhecimento da posse para milhões de moradores em situação informal e/ou irregular no Brasil.

Ademais do exposto, foi também neste período que se intensificou a expansão e a ampliação da disponibilidade de incentivos financeiros públicos para o crédito voltado a produção habitacional. Essa situação, associada ao crescimento da economia, segundo ensinam Denaldi, Leitão e Zioni (2010), representou um dos maiores ciclos de crescimento do segmento imobiliário nas cidades. De outra banda, no entanto, praticamente se estagnou o fluxo migratório do campo para as cidades, o que conduz a conclusão de que a dinâmica da expansão demográfica experimentada no período (e atualmente) tem relação direta com o crescimento vegetativo da população e não mais necessariamente com a vinda para a cidade de cidadãos do campo, como ocorrido em décadas anteriores.

Como a diminuição expressiva do fluxo migratório, ocorreu a consolidação gradativa dos territórios populares (conjuntos habitacionais, favelas e loteamentos periféricos, por exemplo), de sorte que os ambientes que se constituíram, principalmente nas décadas de $60 \mathrm{a}$ 80, com raras exceções, hoje são providos de espaços comerciais, água, luz, serviços públicos. Porém, estes mesmos espaços, em que pese dotados de infraestrutura mínima, hoje são reconhecidos como campos geográficos delineadores da pobreza e vulnerabilidade social, de modo que a sua gestão, por serem atualmente muito mais heterogêneos, igualmente se tornou muito mais complexa, sobretudo por que atualmente representam a precisa definição de qual é o lugar do pobre na cidade.

Em outras palavras, ainda que tenha ocorrido a consolidação destes espaços informais que hoje, em sua maioria, contam com infraestrutura básica e alguns equipamentos sociais, há que se dizer, filiando-se posicionamento de Torres e Marques (2000), que estes espaços ainda são marcados por acentuada precariedade, que se revela, especialmente, na má qualidade da infraestrutura e dos serviços públicos, na ausência de urbanismo, no extenso rol de elementos urbanos que ainda precisam ser feitos ou obtidos, além do estigma territorial e social 
permanente.

Essa realidade é decorrência, principalmente, da adoção de um modelo de Estado que, embora "preocupado" com os direitos sociais, é norteado por bases excludentes, patrimonialistas e predatórias, características que auxiliam no processo de reverberação da crise urbana.

Com efeito, esse modelo de desenvolvimento perverso, com forte influência neoliberal, resultou na consolidação de uma das sociedades mais desiguais de todo o mundo, mormente porque avassaladora parcela da população não tem atendida suas necessidades básicas, como é o caso da habitação e, se a tem, é de forma extremamente precária, o que igualmente repercute na acentuação da crise urbana.

Não há como negar que a nova ordem constitucional urbana inaugurada com a inserção, na Constituição Federal de 1988, dos artigos 182 e 183, tenha criado a base jurídica para a realização do direito à cidade e a efetivação de uma denominada agenda de reforma urbana.

Todavia, para que os objetivos desta nova ordem constitucional urbana efetivamente se concretizassem era preciso muito mais que simples estabelecimento de princípios jurídicos. Dito de outra forma, imperioso para superação da crise urbana que fossem implementadas políticas públicas em larga escala, situação que não poderia ser efetivada sem uma injeção significativa de recursos públicos e uma mudança substancial na política habitacional que, até então, era marcada pela exclusão.

Em que pese o raciocínio estivesse correto, Bercovivi e Massonetto (2006) asseveram que, principalmente em decorrência do cenário econômico global, o governo tomou a direção oposta. Como reflexo desta opção, o Governo adotou um regime fiscal extremamente rigoroso, que teve como resultado a contenção dos gastos públicos na área das políticas para implementação e concretização dos direitos sociais.

Esta postura estatal acentuou o paradoxo havido entre a diminuição da pobreza/crescimento econômico e a agudização da crise urbana.

Segundo salienta Rolnik (2015, p. 271):

Uma expressão repetida incessantemente no país - das campanhas políticas às mesas de bar - oferece uma versão simplificada do paradoxo diminuição da pobreza/crescimento econômico e agudização da crise urbana: da porta para dentro avançamos (leia-se: compramos geladeiras, computadores, celulares, viagens de férias, etc.), da porta para fora estamos cada vez pior (leia-se: dimensão pública, coletiva, das políticas, a infraestrutura social e econômica inexistente, insuficiente ou precária). 
Como reflexo deste paradoxo, a agudização da crise urbana parece se fortalecer, independentemente da opção política dos governos no campo dos direitos sociais. Mais que isso, a crise urbana se intensifica, sobretudo a partir de três pontos principais: mobilidade, violência e habitação.

No campo da mobilidade, conforme já verificado anteriormente, o modelo de desenvolvimento adotado no Brasil tem facilitado a composição de cidades marcadas pela concentração, ou seja, as oportunidades de desenvolvimento econômico e humano costumam estar restritas a determinados setores do território, o que implica na regular expansão das periferias precariamente urbanizadas.

Mais que isto, este modelo de desenvolvimento tem sido "historicamente alimentado por uma política de suporte à circulação de automóveis privados e de manutenção de um sistema de transporte coletivo por ônibus de baixíssima qualidade" (Rolnik, 2015, p. 271-271). O favorecimento da posse do automóvel, que atingiu diretamente a classe média, fez com que aqueles que não tivessem condições de possuir veículo próprio continuassem circulando através do transporte coletivo, como ocorria nas décadas de 30 e 40, só que agora, percorrendo distâncias muito maiores, o que eleva, invariavelmente, o tempo de percurso e o custo.

Segundo Rolnik (2015, p. 272), o "pacto de vida e morte com os automóveis e o desprezo pelo transporte coletivo de massa, aliados ao modelo de cidade concentrador, impõem a imobilidade para o conjunto da sociedade.".

Além da mobilidade, outra face da crise urbana se revela na violência e no medo, que assolam a realidade das cidades brasileiras, principalmente a partir do final da década de 90 . Como visto, o modelo de desenvolvimento adotado a partir da promulgação da Carta Cidadã em 1988, reduziu drasticamente os investimentos no campo das políticas públicas, aumentando a pobreza e a criminalidade.

Essa realidade contribuiu para que o narcotráfico, por exemplo, se infiltrasse com mais intensidade nas cidades, tornando-se uma referência econômica, social e moral. Em decorrência do exposto, também se intensificou a violência e o medo, que acabaram impactando na forma de organização e reestruturação das cidades, "gerando novas formas de segregação espacial e discriminação social: os enclaves fortificados" (CALDEIRA, 2000, p. 9).

Por fim, o terceiro elemento de maior expressão da crise urbana se traduz na questão da habitação. Conforme já abordado anteriormente, o padrão histórico da moradia no Brasil se constitui, basicamente, na construção de conjuntos habitacionais precários nas periferias das cidades, ou no surgimento de ocupações irregulares, as favelas. Essa realidade é resultado do 
caráter patrimonialista que impera na sociedade brasileira, bem como da concentração do poder econômico e político.

Com efeito, é possível verificar que diante da exiguidade de mecanismos compensatórios:

O dinamismo econômico e a distribuição funcional da renda distorcida compõe um coquetel perverso, tendendo a agravar a situação do trabalhador pela exclusão socioespacial, alimentada pela valorização especulativa da terra. (ROLNIK, 2015, p. 278).

Vale dizer que no caso brasileiro o expressivo aumento da disponibilidade de crédito, principalmente crédito imobiliário, contribuiu significativamente para o aumento no preço dos imóveis. Essa situação se intensificou a partir do ano de 2009, com o surgimento do Programa Minha Casa Minha Vida, que disponibilizou 100 bilhões de reais em crédito imobiliário residencial, impactando diretamente no avanço da financeirização do solo urbano e da moradia e, por conseguinte, agravando a crise urbana.

A seguir, portanto, serão analisados os aspectos principais do Programa Minha Casa Minha vida, e quais foram as suas contribuições no processo de financeirização do solo urbano e da moradia no Brasil.

Programa Minha Casa Minha Vida e seus reflexos na crise urbana brasileira

Inicialmente, é necessário ponderar que o processo de financeirização do solo urbano e da moradia influencia diretamente no surgimento de novas dinâmicas políticas. Com efeito, em locais onde se percebe a escassez de recursos para investimento na infraestrutura urbana, seja na sua manutenção ou na sua ampliação, o setor financeiro (mercado) passa a atuar diretamente na política que circunda a escolha pela localização e volume de investimentos públicos em determinado espaço. O surgimento do Programa Minha Casa Minha Vida (PMCMV) se deu exatamente neste contexto.

Desde o ano de 2009, quando foi criado, o Programa Minha Casa Minha Vida ocupa o papel de protagonista no cenário brasileiro da política habitacional, surgindo como uma das várias tentativas feitas pelo Governo de mitigar os efeitos devastadores que a crise financeira mundial de 2008 causou na economia brasileira. A sua implementação tem ocorrido com base na oferta de diferentes modelos de crédito tanto para o consumo quanto para a produção de unidades habitacionais, com vistas a criar condições de ampliação do mercado habitacional.

Segundo esclarece Raquel Rolnik (2015, p. 300), em 2007 já existiam quase 550 mil 
unidades habitacionais financiadas pelo FGTS e, em meados de 2008, o montante dos empréstimos na área habitacional já somavam mais de 40 bilhões de reais, tendo as incorporadoras e empresas do ramo imobiliário "feito grandes estoques de terrenos e, naquele ano, estavam preparadas para lançar por volta de 200 mil habitacionais."

No entanto, quando estourou a crise financeira internacional no ano de 2008 , o setor imobiliário brasileiro igualmente se viu fortemente ameaçado pela falência, situação que, caso ocorresse, poderia contaminar todo o setor produtivo e, de modo consequente, também a estratégia econômica do governo brasileiro.

Como resposta ao problema da crise das empresas do setor imobiliário, conforme Mariana Fix (2011, p. 139), “o governo editou [...] a Medida Provisória 443, de 2008, autorizando o governo, em especial a Caixa Econômica Federal, por meio a criação de uma subsidiária, a comprar ações de empresas da construção civil." Tal medida, porém, não foi bem recebida pelo setor, que chegou a acusar o Governo de estar tentando a estatização.

A partir disso, empresários influentes no ramo, com o apoio da Câmara Brasileira da Industria da Construção, passaram a tentar influenciar decisões do poder pública para beneficiar seus interesses privados. Notadamente, a intenção dos "lobistas" era forçar o Governo a implementar um pacote habitacional, de forma que, consoante aduz Rolnik (2015, p. 300):

Por meio de subsídios diretos ao comprador, o governo viabilizaria a compra das 200 mil unidades que as construtoras capitalizadas estavam preparadas para lançar no mercado - operação que estaria ameaçada pela crise se não houvesse a intervenção estatal. Este subsídios seriam dados na forma de aporte aos compradores finais, além de maior facilidade nos créditos hipotecários, com a introdução de um fundo garantidor de empréstimos.

Ocorre que embora esta narrativa de fatos tenha ocorrido durante a governança de um partido defensor dos direitos sociais, toda a construção da proposta se deu sem a participação do Ministério das Cidades, da equipe que estava elaborando o Plano Nacional de Habitação, do Conselho das Cidades e do Conselho de Habitação ou, ainda, do SNHIS, entidades que já há algum tempo tentavam influenciar nos rumos da política habitacional do país.

Em outras palavras, o único setor interessado que participou diretamente da interlocução foram os empresários e investidores envolvidos, motivo pelo qual este "pacote" inicialmente "tinha como objetivo salvar as empresas da débâcle e, ao mesmo tempo, funcionar como medida contra cíclica para garantir empregos e crescimento num cenário internacional desfavorável" (ROLNIK. 2015, p. 301). Para que isso se tornasse possível, era preciso rechaçar a 
criação de qualquer política muito complexa, que exigisse tempo de maturação ou que pudesse representar alguma resistência, o que invariavelmente ocorreria se fosse adotada uma política fundiária de larga escala.

Superadas estas questões, quando o "pacote habitacional" foi apresentado ao então Presidente Lula, ele logo tratou de politizar as medidas, de sorte que, no lugar de 200 mil casas, propôs a construção de 1 milhão, além de aumentar a parcela do programa que deveria ser dirigida aos setores de mais baixa renda - inicialmente eram $20 \%$ das unidades, já que o principal foco era o "segmento econômico" (faixas de quatro a dez salários mínimos, a clientela potencial desses produtos).

Convencionadas as principais bases do "pacote habitacional", o Governo propôs uma série de reuniões para discuti-lo com alguns setores, antes de realizar o seu lançamento em março de 2009. Nessas reuniões foram feitos alguns ajustes, como, por exemplo, passar a tratar a proposta como "programa" e não mais como "pacote", o que sugeriu a própria escolha do seu nome pela equipe de marketing do Governo.

A partir do seu lançamento, o PMCMV passou a ser tratado como ação prioritária na esfera econômica-social, associando a oferta de moradia, uma reivindicação antiga e valioso ativo eleitoral, com uma estratégia de intervenção estatal na economia para garantir a geração de empregos e para o crescimento econômico.

O PMCMV é divido em quatro núcleos: (1) MCMV - Entidades (destinado a produção de moradias por associações e cooperativas autogestionadas); (2) MCMV - Rural (destinado a construção de casas para pequenos produtores da agricultura familiar); (3) MCMV - Sub 50 (destinado a municípios com menos de 50 mil habitantes); e (4) MCMV - Empresas (oferece linhas de crédito de acordo com a faixa de renda para construção de moradias até determinado valor).

Juntos, o MCMV - Entidades, o MCMV - Rural e o MCMV - Sub 50 representavam menos de $10 \%$ do total de moradias e recursos inicialmente previstos quando do lançamento do Programa, o que faz com a o MCMV-Empresas assuma, verdadeira, o papel de "núcleo duro" desta política pública habitacional.

O MCMV-Empresas é dividido em três faixas distintas, cada uma com condições e valores específicos no que tange aos subsídios ofertados.

A primeira faixa (famílias com rendimento mensal até 1,6 mil reais) disponibiliza a moradia de forma praticamente subsidiada, construída por empresas privadas e distribuídas pelo Governo locais. Nesse caso, os moradores são compelidos ao pagamento de uma taxa 
mensal quase simbólica, que corresponde hoje a cinquenta reais, para a Caixa Econômica Federal, que é o órgão incumbido de comprar as moradias das construtoras privadas. A diferença entre o valor pago pelos moradores e o real custo da casa é coberta pelo Fundo de Arrendamento Residencial (FAR).

A faixa 2 beneficia famílias com renda mensal entre 1,6 mil reais e 3,1 mil reais, que também recebe subsídios públicos, só que em menor grau. A faixa 3 traz benefícios para as famílias com renda mensal de até 5 mil reais. Nesses dois casos, tanto a construção quanto a venda das moradias é feita diretamente pela construtora privada ao consumidor final, cabendo a Caixa apenas financiar a produção e/ou oferecer subsídios para quem tiver interesse em adquirir as moradias.

Em que pese o PMCMV tenha sido um sucesso do ponto de vista dos agentes envolvidos, sobretudo porque o lucro é realizado, o Programa aparentemente foca de forma exclusiva no aspecto econômico da moradia, o que inevitavelmente repercute de maneira negativa no processo de financeirização da moradia e do solo urbano, e tende a agravar a crise urbana. Conforme salienta, Rolnik (2015, p. 309):

De pacote de salvamento de incorporadoras financeirizadas, o MCMV transformou-se na política habitacional do país, baseada no modelo único de promoção da casa própria, acessada via mercado e crédito hipotecário. Abortou-se, assim, a incipiente construção de uma política habitacional diversificada, aderente às especificidades locais e sob controle social, aposta dos movimentos sociais e dos militantes da reforma urbana no início do governo Lula.

Por certo, não há lastro de dúvidas a indicar que, de fato, as empresas do setor imobiliário foram diretamente beneficiadas pelo PMCMV, na medida em que o programa não apenas as salvou da falência como, também, impulsionou significativamente seus empreendimentos e, por consequência, ampliou sua obtenção de lucro. Igualmente, não há dúvidas de que o PMCMV obteve êxito enquanto medida contra cíclica para garantir empregos e crescimento num cenário internacional desfavorável, especialmente na indústria da construção civil, situação que invariavelmente atraiu o apoio de setores sindicais e empresariais.

O êxito na esfera social, porém, não foi tão satisfatório quanto o esperado, o que inclusive pode pôr em cheque a real finalidade do programa. Trata-se verdadeiramente uma política habitacional para fazer cumprir os direitos sociais, ou é apenas uma política econômicofinanceira utilizada para beneficiar entidades e investidores privados?

Vários elementos (que não serão exauridos aqui) conduzem à ideia de que, infelizmente, o PMCMV é uma política econômico-financeira, e não uma política habitacional, 
contradizendo a ideia de que "vendida" à sociedade. Um dos principais elementos que conduzem a esta conclusão é, justamente, a ideia de padronização, isso porque, em face das múltiplas necessidades habitacionais, torna-se praticamente impossível que um único programa de política habitacional resolva toda a demanda por habitação.

A promoção de políticas para aquisição da casa própria por óbvio que deve ser muito bem aceita, todavia, esse único modelo não pode ser aplicado indistintamente para toda a população, especialmente para a população mais pobre, situados na faixa 1 do Programa, pois a realidade tem demonstrado que, ao longo do tempo, a manutenção e gestão destas moradias ou condomínios habitacionais não é sustentável. Não há estrutura física, emocional e financeira para suportar essas incumbências.

De acordo com Rolnik (2015, p. 314), o peso das despesas dos moradores é "ainda maior se considerarmos os gastos com água, luz e gás. Este impacto afeta principalmente reassentados que sofreram remoção forçada, uma vez que a moradia nova traz consigo muitos gastos que antes não tinham."

Mostra-se imprescindível, portanto, que outras alternativas sejam exploradas, sobretudo para atendar a dimensão social da moradia, que sempre deve ser compreendida como um direito humano. Há, exemplo, que se buscar um melhor aproveitamento das inúmeras possibilidades de vínculo com o solo, através da materialização de diferentes formas de posse que possam, ainda que sem o vínculo da propriedade, garantir o direito humano à moradia digna.

Outro efeito colateral que subtrai a essência social do PMCMV reside no fato de que as regras do Programa atribuem à empresa privada o poder de decidir sobre a localização e o desenho do projeto que será desenvolvido. Como já era de se imaginar, o critério que indistintamente tem orientado escolhas desta natureza é o da rentabilidade. Como resultado disso, ocorrem a construção de inúmeros empreendimentos nas piores localizações das cidades, pois nesses locais o solo é mais barato e, assim sendo, a empresa terá maior lucro, situação que agrava ainda mais a segregação socioespacial.

Para além o exposto, outra falha grave apresentada pelo PMCMV refere-se à não oferecer qualquer qualificação para as áreas onde os empreendimentos são construídos a fim de reduzir sua precariedade. De um modo geral, por se situarem em áreas afastadas do centro, estes espaços possuem parcas oportunidades de se desenvolverem econômica e culturalmente, além de manterem a característica de "bairro-dormitório", com frágil qualidade urbanística.

Com efeito, ao longo dos anos a política habitacional exerceu um papel essencial na 
consolidação do modelo urbano das áreas metropolitanas, da mesma forma com que influenciou diretamente na reprodução do padrão de segregação socioespacial. A construção de grandes condomínios habitacionais em regiões periféricas já é tradicional no Brasil e o PMCMV não conseguiu reverter essa lógica (talvez nem tivesse essa intenção).

Para Rolnik (2015, p. 313):

A construção de grandes conjuntos habitacionais em áreas periféricas onde a terra é mais barata - forma de provisão habitacional predominante ao longo de décadas - contribuiu substancialmente para impulsionar o espraiamento urbano, a proliferação de um padrão urbanístico monofuncional e o estabelecimento de uma divisão territorial entre ricos e pobres, apesar dos muitos bilhões de reais em subsídios públicos, o programa MCMV não impacta a segregação urbana existente. Pelo contrário, apenas a reforça, produzindo novas manchas urbanas monofuncionais ou aumentando a densidade populacional de zonas guetificadas já existentes.

Como é possível perceber do exposto até aqui, a produção intensa de moradia "sem cidade" ao longo das décadas acarretou em uma ampla segregação socioespacial além de inúmeros problemas sociais que trouxeram significativos ônus ao poder público, situação que parece ser cíclica, pois está se repetindo novamente, e continuará se repetindo caso novas iniciativas não sejam adotadas para a construção de cidades mais justas, democráticas, inclusivas e humanas.

\section{CONCLUSÃO}

Com base nas análises e informações fornecidas ao longo deste trabalho, é possível perceber que existem importantes fatores de influência que repercutem diretamente nas situações afetas ao direito à cidade, merecendo destaque as influências do capital financeiro neste desenvolvimento urbano, que acaba transformando este importante direito humano em ativo econômico.

Com efeito, a realidade brasileira tem demonstrado que, quando o Poder Público deixa de exercer o seu papel de protagonista na regulação da política pública habitacional, acaba permitindo que o setor privado assuma o comando da situação, dirigindo a regulamentação dessas questões para a satisfação de seus interesses particulares, em detrimento do interesse coletivo.

O mesmo ocorre, vale dizer, quando o Poder Público permite que o setor privado atue como coadjuvante, exercendo influência política e econômica na condução das políticas 
públicas, situação que igualmente acaba desviando a finalidade principal dessas ações situação que ocorreu, como visto, quando da criação do Programa Minha Casa Minha Vida, no ano de 2009.

A repetição do padrão que prioriza os aspectos econômicos em detrimento dos aspectos sociais nos programas habitacionais e um alto déficit habitacional demonstram o insucesso da política habitacional ditada pelo mercado financeiro, e conduzem para o necessário enfrentamento da inevitabilidade de diversificação, ou seja, a conclusão que se impõe diante da análise da conjuntura habitacional do Brasil nos últimos anos revela que pautas únicas (como é o caso de ofertar financiamento) são os principais responsáveis pelo fracasso da concretização da moradia digna.

Em outras palavras, as experiências feitas ao longo dos anos e analisadas neste trabalho evidenciam que para que a política habitacional seja bem sucedida ela precisa ser diversificada, ou seja, é necessário oferecer diferentes soluções, para os problemas que são diferentes em cada família brasileira. Por certo, considerando a imensidão deste país, com regiões climaticamente bem demarcadas e distintas, com aspectos culturais tão relevantes e diversos em cada região e com tantas necessidades e realidades individualizadas, não há como um único modelo de política habitacional ter êxito em toda a sua extensão.

A concretização da cidade enquanto espaço justo, democrático e inclusivo, como se vê, representa tarefa bastante complexa, de sorte que o enfrentamento desta realidade exige a superação de muitos desafios. Com efeito, é nítido que o desafio para superar essa situação de crise urbana que se mostra quase insustentável se reflete na necessidade de combinar a adoção de estratégias e medidas de inclusão social que evidenciem a democracia, a equidade e a descentralização, de modo que sejam melhor valorizados os aspectos do desenvolvimento local, viabilizando o surgimento de cidades mais ideais.

Em que pese toda a problemática analisada, e as críticas aventadas ao longo deste trabalho, é importante reconhecer, sobretudo para evitar injustiças, que o País produziu consideráveis avanços na área habitacional nos últimos anos, viabilizando a melhoria na qualidade de vida de uma parcela expressiva da população. No entanto, as lacunas verificadas durante todo o curso da história até os dias de hoje demonstram que ainda existem graves problemas a serem superados para que se tornem reais as cidades mais humanas, desmercantilizadas e que prestigiem com prioridade os aspectos sustentáveis do direito à moradia digna. 


\section{REFERÊNCIAS}

BERCOVIVI, Gilberto; MASSONETTO, Luís Fernando. A constituição dirigente invertida: a blingadem da constituição financeira e a agonia da constituição econômica. Boletim de Ciências Econômicas, v. 49, 2006.

BONDUKI, Nabil. Política habitacional e inclusão social no Brasil: revisão histórica e novas perspectivas no governo Lula. Revista Eletrônica de Arquitetura e Urbanismo. São Paulo, n.1, p.70-104, 2008.

Disponível em: <http://www.usjt.br/arq.urb/numero_01/artigo_05_180908.pdf.>. Acesso em: 15 ago. 2017.

BRASIL. Constituição (1988). Constituição da República Federativa do Brasil. Brasília: Senado Federal 1988.

Disponível em:<http://www.planalto.gov.br/ccivil_03/Constituicao/Constituicao.htm>. Acesso em: 02 jul. 2017.

CALDEIRA, Teresa Pires do Rio. Cidade de muros: crime, segregação e cidadania em São Paulo. São Paulo, Editora 34/Edusp, 2000.

CASTELLS, Manuel. A questão urbana. Rio de Janeiro: Paz e Terra, 2000.

DAVIS, Mike. Planeta Favela. São Paulo: Biotempo, 2006.

DENALDI, Rosana; LEITÃO, Karina; ZIONI, Silvana. Nota técnica: infraestrutura e desenvolvimento urbano. Em Tânia B. Araújo (org.), Trajetórias do Brasil Frente aos Compromissos assumidos pelo governo Lula 2003 a 2009, dimensão melhoria da qualidade de vida. Brasília: CGEE, 2010.

DOUZINAS, Costas. O fim dos direitos humanos. São Leopoldo: Unisinos, 2009.

FIX, Mariana. Financeirização e transformações recentes no circuito imobiliário no Brasil. Tese de Doutorado em Desenvolvimento Econômico. IE-Unicamp. Campinas, 2011.

LEFEBVRE, Henri. O direito à cidade. São Paulo: Centauro, 2011. 
MARICATO, Ermínia. O impasse da política urbana no Brasil. Petrópolis: Vozes, 2011.

ROLNIK, Raquel. Para além da lei: legislação urbanística e cidadania (São Paulo 1886-1936). In: Maria Adélia A Souza; Sonia C. Lins; Maria do Pilar C. Santos; Murilo da Costa Santos. (Org.). Metrópole e Globalização-Conhecendo a cidade de São Paulo. São Paulo: Editora CEDESP, 1999. O que é cidade. São Paulo: Brasiliense, 1995.

(org.). Estatuto da Cidade: guia para implementação pelos municípios e cidadãos. Brasília: CAIXA/Instituto Polis/Senado Federal, 2002.

Democracia no fio da navalha: limites e possibilidade para a implementação de uma agenda de reforma urbana no Brasil. Revista Brasileira de Estudos Urbanos e Revionais, v. 11, n. 2, 2009.

ROLNIK, Raquel; CYMBALISTA, R.; NAKANO, A.K. Solo urbano e habitação de interesse social: a questão fundiária na política habitacional e urbana do país. Revista de Direito da ADVOCEF, São Paulo, v.1, 2011.

ROLNIK, Raquel; NAKANO, Kazuo. "As armadilhas do pacote habitacional". Le Monde Diplomatique, Brasil, 2009

ROYER, Luciana de Oliveira. Financeirização da política habitacional: limites e perspectivas. São Paulo: Annablume, 2014.

SANTOS, Milton. A Urbanização Brasileira. 5. ed., 3a reimpr. São Paulo: Editora Universidade de São Paulo, 2013.

Pensando Espaço do Homem. 5. ed., 3. reimpr. São Paulo: Editora da Universidade de São Paulo, 2012

Trabalho enviado em 07 de julho de 2018

Aceito em 19 de novembro de 2018 